\title{
A CASE OF MYXOMA OF THE LEFT AURICLE
}

\author{
BY \\ R. B. THOMPSON \\ From the Royal Victoria Infirmary, Newcastle-on-Tyne \\ Received September 12, 1943
}

In their paper on this subject Fawcett and Ward (1939) remark that only rarely do descriptions of this interesting lesion appear in British publications, there being only one report in the nine years preceding their article. The condition is well reviewed in their paper and in that of Gilchrist and Millar.(1936). It is the purpose of this article to describe a further case with an autopsy report.

\section{DESCRIPTION OF THE CASE}

The patient, a woman of 33 years of age, was admitted to hospital with severe cardiac failure. There was a story of " growing pains" at the age of 17 , but no history of rheumatic fever or of chorea. The family history was of no significance.

Her earliest complaint, which was of shortness of breath on exertion, started a year before admission; there was also a two-months' story of palpitation and swelling of the feet in the evenings. She managed to continue her work about the house until five weeks before admission, when on her doctor's advice she retired to bed. All these symptoms continued with the addition of a productive cough, loss of appetite, thirst, a feeling of "fullness and wind " in the abdomen, and great discomfort when lying flat in bed, this necessitating her being propped up on pillows.

On examination she was dyspnœic and cyanosed with an obvious malar flush. The neck veins were greatly distended but were not pulsating. There was no clubbing of the fingers. There was a mild degree of œdema of the legs, sacrum, and back, up to the rib margins. A large smooth tender liver could be palpated three fingers below the right costal margin; there was no demonstrable pulsation. No splenic enlargement could be made out, examination being hindered by a well-marked ascites. The pulse was very feeble, its rate being approximately $130 \mathrm{a}$ minute with bouts of irregularity due to extrasystoles. There was no palpable thickening of the radial arteries and the blood pressure was $120 / 80$. To percussion the heart was enlarged both to the right and to the left. The cardiac impulse was forceful and diffuse, in marked contrast to the quiet pulse. There was a systolic murmur, maximal at the apex and radiating diffusely, a loud pulmonary second sound, and then a mid-diastolic

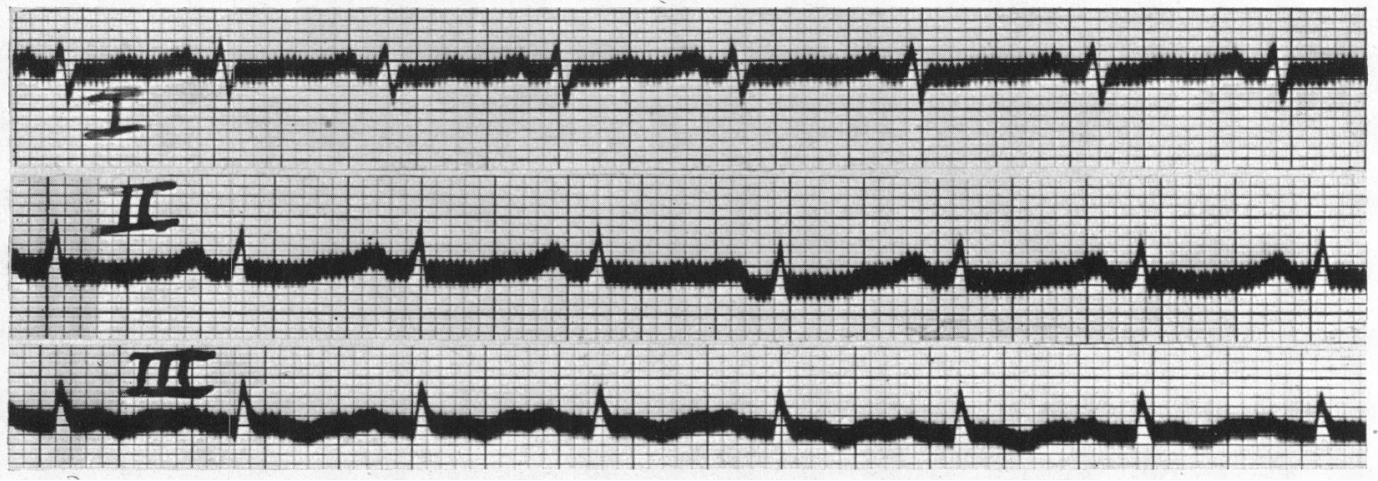

FIG. 1.-Electrocardiogram showing general low voltage response ; none of the extrasystoles that were noted clinically are seen in this record. 
" filling type" murmur heard best internal to the apex. The bases of both lungs were dull to percussion, and crepitations were generalized but most marked at the bases posteriorly.

On these findings a diagnosis of mitral stenosis and heart failure was made. There was no response to digitalis and diuretin, and mersalyl failed to bring about a diuresis, the œdema steadily increasing. Terminally she developed coupling and tripling of the beats and digitalis was withdrawn. During her stay she was very drowsy. A cardiogram showed general low voltage (Fig. 1); no radiological examination was possible.

On the evening of the fourth day she suddenly had an attack of intense dyspnœa and began coughing up a considerable amount of clear frothy fluid. Death occurred in about five minutes.

\section{Pathological Report (Abstract)}

The body was of a well-developed and fairly well-nourished subject; there was œdema of the lower extremities. The pericardial cavity was enormously enlarged, measuring $22 \mathrm{~cm}$. from apex to base, $15 \mathrm{~cm}$. transversely, and $12 \mathrm{~cm}$. antero-posteriorly. It contained about 150 c.c. of.clear fluid. The heart was enlarged, especially on the right side, and the apex was formed by the greatly enlarged right ventricle. The right auricle was distended by $84 \mathrm{~g}$. of post-mortem clot; no ante-mortem thrombi were present. The right ventricle was dilated and hypertrophied to a thickness of $0.8 \mathrm{~cm}$. measured midway between the apex and the base. The dilated pulmonary ring measured $9 \mathrm{~cm}$. The tricuspid and pulmonary cusps were normal. The left auricle was much dilated and largely filled by an enormous myxoma (Fig. 2). This

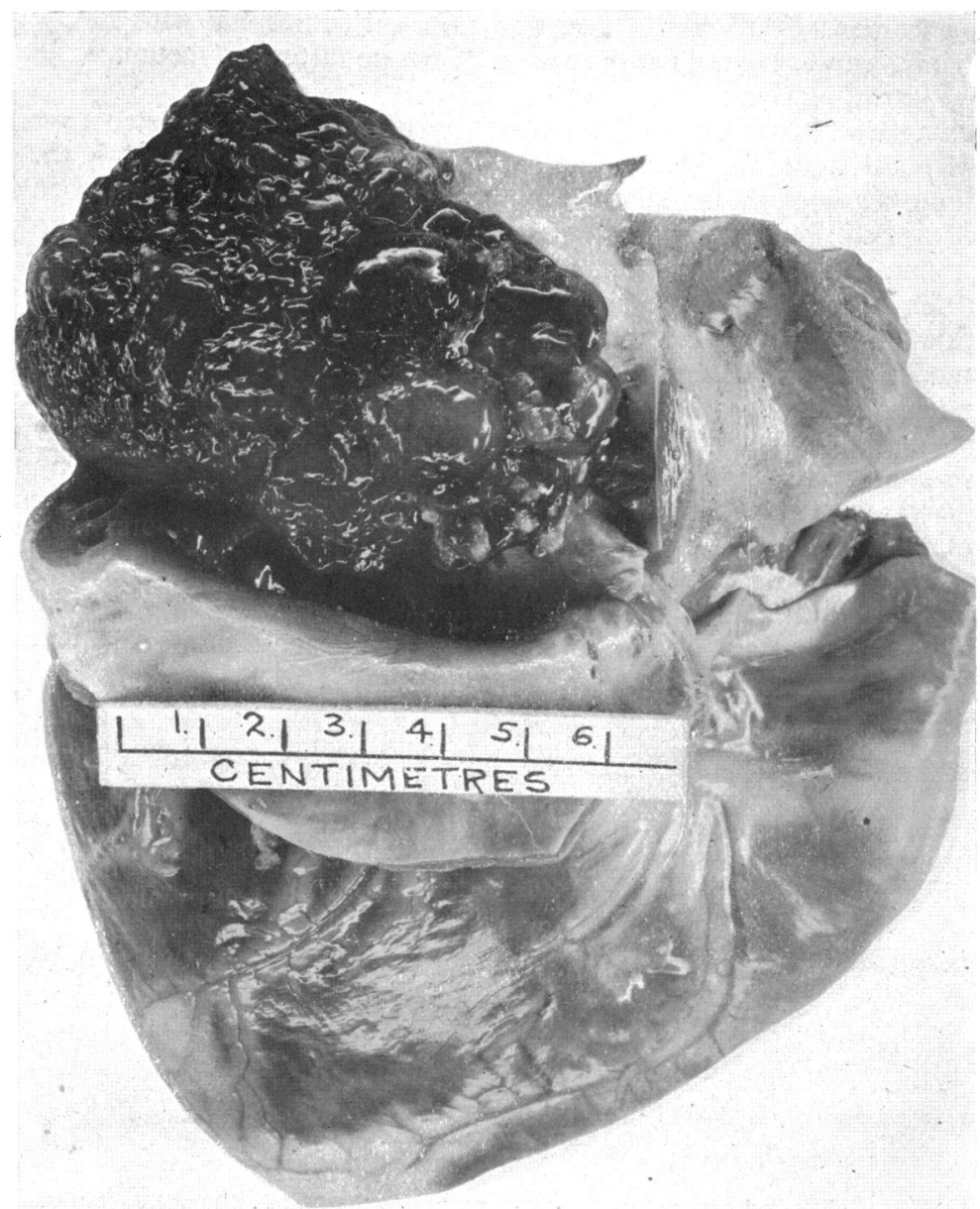

FIG. 2.-Photograph of the heart with the tumour in situ. The specimen is fresh and unfixed. 
measured $7.5 \mathrm{~cm}$. transversely, $5.9 \mathrm{~cm}$. from above downwards, and was $5.5 \mathrm{~cm}$. thick. It was adherent to the septal wall of the left auricle by a narrow pedicle $1 \mathrm{~cm}$. in diameter. Although not actually touching it, this pedicle was attached just opposite the left edge of the foramen ovale. Except for a few small areas of white and red clot this tumour presented externally a very translucent surface partly smooth and partly rippled. There was no mitral stenosis, the valve admitting four fingers easily, and there were no ante-mortem thrombi in the auricle apart from those on the surface of the myxoma.

The myxoma had sufficient freedom to press against the left auricular wall opposite the mitral valve, where occlusion must have been very marked. Apart from this it practically filled the auricle, and only the auricular appendix and the actual mitral orifice were not filled by growth. The pulmonary veins must have been obstructed, and only one, the left inferior, seemed to have escaped obstruction by the myxoma.

The left ventricle, in contrast to the right, was short and atrophic. The heart and the myxoma weighed $450 \mathrm{~g}$.

The lungs showed the induration of chronic venous congestion with an intense œdema and some recent infarcts; the right weighed $840 \mathrm{~g}$., the left $650 \mathrm{~g}$. The main pulmonary arteries showed slight dilatation but no atheroma. The liver had a well-marked nutmeg appearance. Other organs also showed signs of congestion and numerous infarcts of varying ages. The serous sacs contained a moderate amount of clear transudate.

Microscopically the tumour showed the appearances typical of myxoma, with long pro-

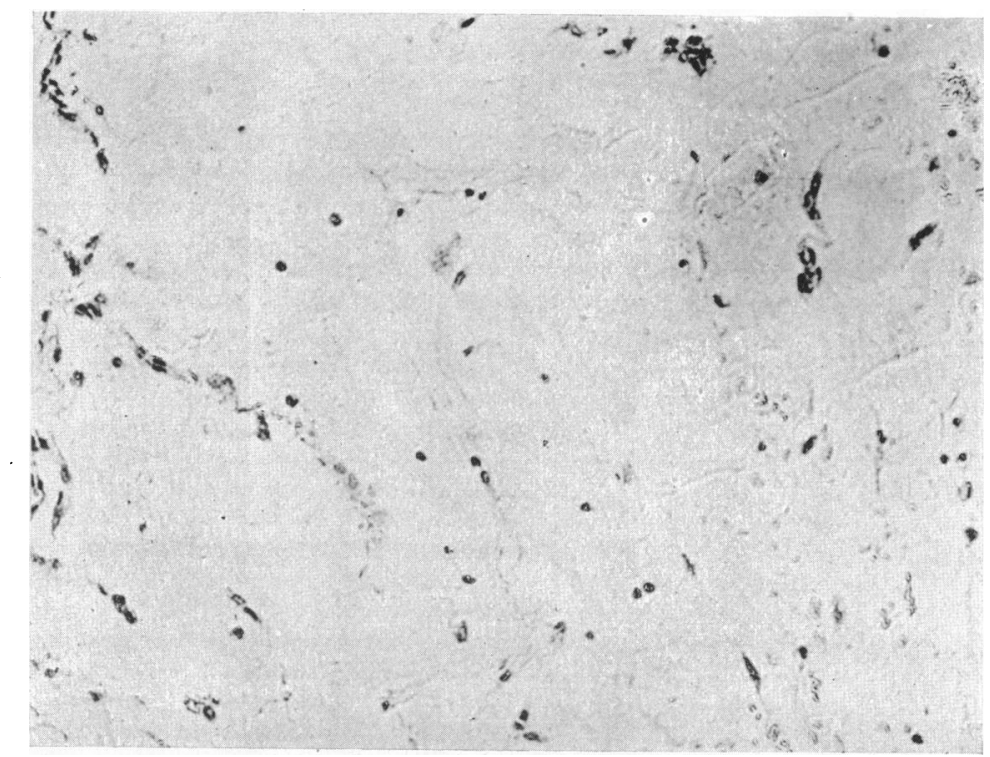

Fig. 3.-Microphotograph of a section of the tumour stained by Weigert's iron hæmatoxylin and van Gieson. Magnification $\times 180$.

cessed myxoma cells rather widely scattered in a pale staining hyaline matrix; nuclear irregularities and mitoses were not seen. It was covered by a layer of endothelium, but here and there this was lacking, being replaced by thrombus (Fig. 3). Some of these areas contained a little hæmosiderin, but elsewhere, including all the deeper parts of the tumour, there was no pigment, fibrous tissue, or other indication of organized blood clot.

\section{Comment}

There have been a great many arguments as to whether these cases are true tumours or organized thrombi; the papers of Hamilton-Paterson and Castleden (1942), of Fawcett and Ward (1939), and of Yater (1931) summarize these discussions. There can be little doubt 
that the mass in the auricle in the present case was a true myxoma. The naked eye and microscopical appearances were of myxoma, and there was no lesion such as mitral stenosis present to account for thrombosis. There was no evidence of rheumatic infection. Again it arose from the characteristic site-the margin of the foramen ovale-where myxomatous rests have been found (Ribbert, quoted by Fawcett and Ward). There was no deep siderosis or fibrosis which would suggest that the mass was an organized thrombus.

The tumour must have been of slow growth and long duration. The chronic venous congestion was as marked as in the average case of mitral stenosis, and as the patient had cardiac symptoms a year before death the tumour must then have been large enough to cause such symptoms and the chances are that it was not then much smaller than it was at death. The infarcts in the organs in the systemic circulation were considered the result of detachment of clot from the surface of the growth; most of them were recent.

Certain of the features of this case are of interest as having been found in records of other patients with this lesion. The case of Gilchrist and Millar died suddenly as did this one, and a similar mode of death has been not infrequent in previous reports. The mechanism in this case would appear to have been a settling down of the tumour in the mitral orifice, this giving rise to a picture like acute left ventricular failure with pulmonary œdema. Other cases have been reported as being liable to attacks of paroxysmal dyspnœa. Sudden death may occur in patients with or without a previous cardiac history (Yater, 1931).

No story of postural fainting attacks or of pain was elicited. It was not noted whether any alteration in the murmurs took place with change of posture. There was no response to treatment, this being in accordance with the usual reports.

The commonest clinical diagnosis is of mitral stenosis, for the condition of auricular myxoma is so rare that it is not likely to be considered, and the picture produced by the mass obstructing auricular blood flow is very similar, in this case no doubt producing the mid-diastolic murmur. Gilchrist and Millar remark ". . . occasions may arise in the presence of heart disease of unknown ætiology, particularly if symptoms be unusual and physical signs difficult to interpret, when the diagnosis might well come to mind, perhaps most readily by a process of exclusion."

\section{SUMMARY}

A case of myxoma of the left auricle with congestive heart failure and sudden death is presented with an autopsy report.

My thanks are due to Dr. J. G. Thomson for his kindness in giving me the use of his autopsy report, and to Dr. J. C. Spence to whose ward the case was admitted.

\section{REFERENCES}

Fawcett, R. E. M., and Ward, E. M. (1939). Brit. Heart J., 1, 249.

Gilchrist, A. R., and Millar, W. G. (1936). Edin. med. J., 43, 243.

Hamilton-Paterson, J. L., and Castleden, L. I. M. (1942). Brit. Heart. J., 4, 103.

Yater, W. M. (1931). Arch. intern. Med., 48, 627. 